Motrivivência Ano XXV, No 40, P. 41-50 Jun./2013

http://dx.doi.org/10.5007/2175-8042.2013v25n40p41

\title{
AS AULAS DE EDUCAÇÃo FÍSICA NA CLASSE ESPECIAL NA ABORDAGEM PSICOMOTORA
}

Roberta Bevilaqua de Quadros'

\section{RESUMO}

O estudo baseia-se em um relato de experiência das aulas de Educação Física de uma turma de Classe Especial, visando demonstrar a importância desta disciplina como prática pedagógica, seguindo a abordagem psicomotora. A classe em questão era formada por seis crianças com necessidades educacionais especiais, e ocorriam duas vezes por semana, uma juntamente com uma turma de classe regular. Através do planejamento e execução das aulas constatou-se a importância do componente curricular educação física, pois os alunos vivenciaram atividades que privilegiaram a cooperação, criatividade e coletividade, refletindo no desenvolvimento motor, cognitivo, e afetivo-social.

Palavras-chave: Abordagem Psicomotora; Classe Especial; Educação Física Escolar. 


\section{INTRODUÇÃO}

O ser humano possui diferentes características, e dentre elas, a capacidade de expressão, atitudes em relação ao ambiente em que se encontra, e para isso acontecer deve-se haver percepção corporal, temporal e espacial. Nessa perspectiva, a psicomotricidade envolve o individuo em todas essas percepções, estimulando-os a evolução dessas no decorrer de sua aplicação.

As aulas de Educação Física necessitam de planejamento e comprometimento para que os alunos sejam estimulados no seu desenvolvimento de capacidades e habilidades nos domínios motor, cognitivo e afetivo-social. Nesse sentindo, sustentou-se a prática pedagógica através da abordagem psicomotora para subsidiar as aulas para a classe especial, a fim de que a psicomotricidade das crianças seja estimulada e desenvolvida.

Azevedo e Shigunov (2000) relatam que a Abordagem Psicomotricista para o processo de ensino-aprendizagem emprega atividades lúdicas, sendo de forma espontânea e exploratória da criança e suas relações com seus colegas, obedecendo às estratégias e planejamento dessa abordagem. Os mesmos autores alegam que a abordagem psicomotora compreende que: os conteúdos são vivências de tarefas motoras; a temática principal abrange a aprendizagem e desenvolvimento motor; a estratégia metodológica abrange a estimulação das capacidades perceptivas motoras; e a avaliação como observação sistematizada.

A disciplina de Educação Física deve respeitar e considerar as diferenças individuais de cada aluno, possibilitando a inclusão de todos nas aulas independentemente de deficiência, etnia, sexualidade, gênero, poder aquisitivo, entre outros. Ballard (1997) citado por Sanchez (2005) defende que todos os alunos possuem o mesmo direito a ter acesso a um currículo culturalmente valioso, em tempo completo e de acordo com a idade em uma classe escolar.

A esse acesso ao currículo da disciplina de Educação Física que refletimos com o desenvolvimento do subprojeto na escola, houve a preocupação do comprometimento no desenvolvimento de ensino-aprendizagem com todas as turmas da escola. Nesse sentido, a inserção de acadêmicos ministrando aulas dessa disciplina como atividade complementar para o ensino fundamental séries iniciais e finais teve como preocupação de expandir essas aulas para a turma da classe especial, o qual se justificou pelo fato dessa turma não ter acesso à disciplina em questão.

Neste contexto o objetivo desse estudo visa demonstrar a importância da Educação Física Escolar como prática pedagógica na turma da classe especial, seguindo a abordagem psicomotora, a fim de estimular os domínios: cognitivo, motor, e afetivo-social dos alunos.

\section{EDUCAÇÃO FÍSICA ESCOLAR E A ABOR- DAGEM PSICOMOTORA}

As ações psicomotoras envolvem capacidades e habilidades que o indivíduo adquire e desenvolve no aspecto cognitivo, motor e afetivo-social. Monteiro (2007) remete que a ligação entre a Educação Física escolar com a psicomotricidade é baseada nas necessidades do indivíduo integrar-se com si própria e com o ambiente através dos movimentos e experiências adquiridas nas etapas de sua vida. 
No âmbito da escola, a disciplina de Educação Física exerce papel relevante para o desenvolvimento da criança, sendo esse um espaço para entender o seu corpo e a relação com o meio que a cerca. Fonseca (1988) cita que a aprendizagem escolar pode ser auxiliada pela Abordagem Psicomotora nas aulas de Educação Física sendo fundamental para favorecer atitudes e transformações nas ações psicomotoras do ser humano.

Lima e Barbosa (2007) colocam que a relação entre a Educação Física escolar e a psicomotricidade baseia-se nas necessidades que o individuo possui em integrar-se consigo mesmo e com o ambiente por meio de suas vivências. Os mesmos autores ainda ressaltam que a abordagem psicomotora na educação infantil faz como que a criança compreenda a sua consciência e expressão corporal, localizando-se no tempo e no espaço, fazendo que o movimento humano transforme-se em um comportamento significante, respeitando as etapas do seu desenvolvimento.

No momento em que a criança consegue compreender-se enquanto corpo no meio em que esta inserida, a mesma consegue perceber com mais facilidade o significado do seu corpo em relação a espaço, tempo, expressão e consciência corporal, de uma forma global.

A interação entre corpo e espaço vem a contribuir à resolução de situações problemas, a capacidade de memorização, raciocínio, as trocas de informações, interação entre as pessoas do seu convívio, demonstrações de suas emoções, entre outros. As atividades são realizadas não somente em sua prática, fazer por fazer, e sim, fazendo com o que aluno interaja e compreenda o que esta sendo realizado. Barreto (2000) defende que a psicomotricidade é essencial para prevenção dos problemas de aprendizagem, reeducação do tônus muscular, da postura, lateralidade e ritmo.

As atividades com base na psicomotricidade auxiliam a criança nas áreas psicomotoras, as quais irão refletir no desenvolvimento da aprendizagem, evitando quando estimuladas, problemas na alfabetização (leitura, escrita, falta de concentração), quando o esquema corporal da criança não é desenvolvido. Monteiro (2007) cita que o crescimento da criança abrangendo a aprendizagem e a maturação de potencialidades é de responsabilidade de a escola promover esse desenvolvimento.

A criança no seu ambiente escolar deve ser respeitada em relação a seus limites, cultura corporal e seus interesses. Sendo que esta abordagem deve ser trabalhada nas percepções afetivas, audiovisual, visomotora, de lateralidade e espaço, equilíbrio, respiração, coordenação motora ampla e fina. O professor de Educação física precisa valer-se de informações e estar disposto a executar um trabalho diferencial a fim de estimular o processo de ensino-aprendizagem de seus alunos.

\section{EDUCAÇÃO FÍSICA ESCOLAR E A CLASSE ESPECIAL}

O atendimento educacional às pessoas com deficiência e necessidades educacionais especiais foi fundamentado pela Lei de Diretrizes e Bases da Educação Nacional, Lei $n^{\circ}$. 4.024/61, em 1961, com ênfase aos direito dos excepcionais à educação, preferencialmente dentro do sistema geral de ensino. Mas esta Lei foi alterada pela Lei $n^{\circ}$. 5.692/71, por definir tratamento especial 
para os alunos com deficiências, assim não promovendo a organização de um sistema de ensino capaz de atender os mesmos e acabando por reforçar o encaminhamento destes para as classes e escolas especiais.

Conforme Brasil (2008) a educação especial organizou-se como atendimento educacional especializado substitutivo ao ensino comum, demonstrando diferentes compreensões, as quais impulsionaram a criação de instituições especializadas, escolas especiais e classes especiais. É uma modalidade de ensino que transcorrem níveis, etapas e modalidades, disponibilizando serviços e recursos próprios do atendimento educacional especializado, orientando alunos e professores quanto ao seu emprego nas turmas comuns do ensino regular.

Com essas medidas, as crianças e jovens que apresentam algum tipo de necessidade educacional especial ou deficiências passaram a ter o direito de ingressar em turmas regulares nas escolas. Conforme Beyer (2003) a escola inclusiva ou a escola com uma proposta de inclusão escolar tem de atender todas as crianças, sem qualquer exceção, não determinando distinções de espécie alguma, no que tange às características diversificadas de aprendizagem de seus alunos.

Arantes (2005) cita que com a transformação de concepção na educação, o processo de escolarização permitiu que as pessoas com necessidades especiais pudessem ser incluídas no processo ensino-aprendizagem. A mesma autora defende que a Educação Física deve atender todas as pessoas, principalmente as que necessitam de atendimento individualizado nos diversos tipos de situações, como deficiência, obesidade, entre outros.
As aulas de Educação Física podem oferecer atividades para estimular o desenvolvimento dos domínios cognitivo, afetivo e social dos seus alunos, respeitando as limitações. Nessas aulas, a participação dos alunos nas atividades é imprescindível para que haja um desenvolvimento em suas capacidades e habilidades e interação no convívio entre os colegas.

Oliveira e Duarte (2001) remetem a importância da utilização dos jogos e brincadeiras na disciplina de Educação Física para pessoas com necessidades educacionais, pelo simples fato de valorizar e inserir seus conteúdos, suas estratégias intrínsecas à própria brincadeira. Nesse sentido, devemos dar ênfase nas atividades que possibilitem o auxilio entre os colegas, vibrar com a mesma, reclamar e questionar o porquê aconteceu o erro, dentre outros elementos presentes nos jogos e brincadeiras, que permitem que o processo de sociabilização ocorra de uma forma tranquila.

O professor de Educação Física pode garantir condições de segurança para o aluno com Necessidades Educacionais Especiais (NEE), fazendo adaptações, criando situações de modo a possibilitar a sua participação, sempre visando todas as maneiras que favoreçam o princípio da inclusão. Propiciando o desenvolvimento e o aperfeiçoamento motor de seu aluno, onde se encontram: a força muscular; a coordenação motora; a flexibilidade corporal; o equilíbrio motor; a velocidade e a resistência e além do desenvolvimento motor, buscando favorecer a formação humana e a afetividade dos alunos, como responsabilidade, cooperação, respeito pelos outros, solidariedade, organização, criatividade, confiança em si mesmo (GALLARDO apud FALKENBACK e MEDEIROS, 2008, [s.p]). 
Cidade e Freitas (1997) defendem que o professor deve ter conhecimentos sobre seus alunos no que se refere à individualidade e limitações, como o tipo de deficiência, a causa, as restrições clínicas, e outros que seja essencial saber. A informação sobre os alunos que compõem a classe tanto especial ou regular é fundamental para que o professor possa planejar suas aulas de acordo com as características da turma, e para que não haja nenhuma situação desagradável para o aluno, para os colegas, e para a família.

Conforme Oliveira (2002) o professor de Educação Física precisa preocupar-se em desenvolver as potencialidades de seus alunos, que possuem algum tipo de NEE e não excluir das aulas, com a intenção de preservá-los.

Gaio (2006) cita que nas aulas de Educação Física é preciso acreditar e atuar para que todos os alunos com deficiência ou NEE sejam inseridos, para que possam participar no ambiente escolar, juntamente com seus colegas.

É preciso criar condições pedagógicas que facilitem a participação dos alunos, pois todos possuem o mesmo direito de participar de momentos como: aulas, ou atividades na sociedade, entendendo que todos somos diferentes, e que essa diferença é normal.

\section{DESENVOLVIMENTO DAS AULAS}

O estudo foi desenvolvido através do Programa Institucional de Bolsa de Iniciação à Docência (PIBID/CAPES), com o subprojeto "Cultura Esportiva na Escola". O referido subprojeto tem em sua essência estimular os acadêmicos em formação inicial em convívio com a docência na escola de forma complementar, integrando a Universidade Federal de Santa Maria /Centro de Educação Física e Desportos e a escola, na área da Educação Física Escolar.

Ao iniciar o trabalho na turma da classe especial de alfabetização foi realizado um diagnóstico inicial, através de observações para coletas de dados na escola em que se atuou. A primeira sondagem foi realizada com questionamentos para a professora responsável, a fim de conhecer os alunos na questão da idade, quais suas NEE e quais atividades que mais gostavam de realizar.

A turma era composta por seis alunos, sendo eles 2 meninos e 4 meninas, todos na faixa etária entre 9 e 10 anos, de modo que um aluno apresenta Síndrome de Down e os demais Transtorno Global do Desenvolvimento.

Tendo essas informações como base iniciou-se a intervenção na turma através de atividades lúdicas com base na abordagem psicomotora, buscando perceber o nível em que se encontravam os alunos em relação aos aspectos motor, cognitivo e afetivo social. Assim, para-a escolha das atividades e execução nas aulas de Educação Física, tivemos como base as áreas psicomotoras. Monteiro (2007) aponta as seguintes áreas psicomotoras: a coordenação motora fina refere-se na manipulação e controle de objetos, como exemplo a manipulação de um pião. A coordenação motora global implica no controle da realização de movimentos amplos, como chutar uma bola. A estruturação espacial é ter noção e percepção de espaço do próprio corpo e também com o meio externo. A organização temporal é a noção e percepção temporal de seus movimentos e ritmos. A estruturação corporal 
refere-se ao conhecimento e controle do próprio corpo, abrange a imagem corporal, o conhecimento corporal e o esquema corporal. A lateralidade são as noções de esquerda e direita em relação ao corpo.

Nas intervenções das aulas de Educação Física a professora da turma acompanhava as duas acadêmicas bolsistas que ministravam essas. As atividades complementares de Educação Física eram planejadas antecipadamente, com base nas observações realizadas anteriormente, enfatizando o trabalho nos aspectos em que as crianças apresentavam maiores dificuldades.

$\mathrm{O}$ trabalho era realizado de formas diferenciadas em dois dias da semana, sendo nas quartas-feiras no horário das $13 \mathrm{~h} 15 \mathrm{~min}$ às $14 \mathrm{~h}$, e nas quintas-feiras, no horário das $14 \mathrm{~h}$ às $14 \mathrm{~h} 45 \mathrm{~min}$. A primeira aula da semana acontecia tanto na sala de aula como no pátio e na pracinha da escola, apenas com os alunos da classe especial, englobando conteúdos sobre esquema corporal (consciência e controle do corpo), orientação espaço-temporal, lateralidade e coordenação motora (ampla e fina), embasados na abordagem psicomotora. A segunda aula da semana acontecia no ginásio da escola, em conjunto com o primeiro ano das séries iniciais da classe regular. Além dos conteúdos citados acima, era priorizada a integração da classe especial com a turma de classe regular que realizava as atividades em conjunto. As atividades eram realizadas destas formas em busca de um trabalho específico com cada aluno e suas dificuldades, além da socialização e inclusão das duas turmas em questão.

As aulas eram formuladas de modo que, inicialmente realizava-se um diálogo inicial sobre o que seria trabalhado (atividades, materiais, objetivo); logo após, eram efetuadas as tarefas, para finalizar concretizava-se com uma atividade de relaxamento e uma conversa final. Ao findar da aula competia às acadêmicas efetuar um parecer sobre a avaliação da aula, dos alunos em relação às atividades propostas.

As atividades baseavam-se no trabalho em grupo, buscando ser dinâmicas e criativas, de modo que todos se respeitavam, aceitando as diferenças e limitações existentes.

Algumas das atividades realizadas foram: construção do João bobo, petecas, manuseio com balões e piões, estafetas, cantigas, jogos em grupos, recortes, juntamente com a utilização de diversos materiais como cones, cordas, bolas de diferentes tamanhos, desenhos, goleiras, colchonetes, aparelho de som, enfim todos os materiais que auxiliaram no desenvolvimento das atividades.

\section{AVALIAÇÃO DO TRABALHO}

As avaliações das aulas de Educação Física foram guiadas pelas áreas psicomotoras evidenciando os domínios cognitivos, afetivo, social e motor dos alunos no que tange a coordenação motora ampla e fina, na percepção espaço-temporal, na consciência e esquema corporal. Monteiro (2007) deixa claro que a Educação Física não abrange somente os aspectos corporais devido a pratica estar ligada a aprendizagem, com isso o aluno pode ser estimulado nos aspectos cognitivos, afetivo e corporal.

Em cada final de aula anotávamos informações referentes aos alunos e sobre o seu andamento. Além disso, ocorria diálogo entre as acadêmicas para uma melhor reflexão sobre o andamento das atividades, 
a fim de um planejamento mais especifico e qualificado. As anotações e reflexões aconteciam a partir das observações em relação aos domínios motores, cognitivos e afetivo-sociais dos alunos.

A turma apresentava características diversas, na qual alguns se sobressaíam mais que os outros, tanto no que se referia ao aspecto motor e cognitivo quanto ao afetivo-social. Nas primeiras aulas, durante as atividades, tivemos a preocupação de interagirmos com os alunos, aproximando-nos mais afetivamente para que obtivéssemos suas atenções e carinho.

Nas primeiras aulas realizadas na classe especial em conjunto com outra turma, notou-se que os mesmos expressaram muita timidez, buscando ficar sempre juntos e se distanciando do restante dos colegas. Mas no decorrer das aulas, tal situação se modificou, de modo que ambas as turmas se integraram, e se ajudavam na realização das atividades, o que resultou numa melhor e maior evolução do desenvolvimento global dos alunos constituintes da classe especial, em comparação de quando realizavam as aulas sozinhas.

A interação de duas turmas diversificadas em suas características é essencial para que haja uma vivência enriquecedora, principalmente no que tange a individualidade, diversidade, cidadania e cooperação. Mazzotta (2008) explica que para o indivíduo se constituir como pessoa é fundamental a convivência respeitosa de uns com os outros, implicando no reconhecimento do valor de cada ser humano, agindo no sentido de igualdade de oportunidades, de forma que saibam agir nas situações específicas.

No aspecto motor era notável a dificuldade de alguns alunos da classe especial em atividades que englobavam movimentos como correr, saltar, pular, equilíbrio, noções de lateralidade, noção espaço-temporal e noções de corpo. Essas dificuldades encontradas em alguns alunos eram como realizar de forma completa e continua. Neste contexto, procurava-se a realização de atividades que visavam à meIhoria das ações desses movimentos a partir de uma sequência organizada. Com o andamento das aulas, perante efetuação dessas tarefas percebeu-se a evolução motora dos mesmos, onde os que tinham limitações nas ações dos movimentos citados a cima, conseguiram realizá-los, sem dificuldades.

No aspecto cognitivo, percebia-se a dificuldade dos alunos em compreender e memorizar as atividades solicitadas, assim, em cada atividade era retomado a explicação da mesma para um melhor entendimento, a fim de estimular a capacidade de memorização. Durante as aulas, os estudantes contribuíam com suas informações em relação às tarefas que estavam sendo realizado no determinado momento. De modo que quando eram questionados sobre o que estavam fazendo, sabiam responder adequadamente e acrescentavam mais conhecimentos em relação ao seu cotidiano. Durante a aula, sempre dávamos atenção aos alunos, fazendo com que eles refletissem sobre o que estavam realizando e também que tivessem noção sobre seus comportamentos. Estimulou-se a atenção e o convívio harmonioso com colegas tanto pertencentes à classe especial, como os da turma regular. Conforme Sayão (2002) citado por Nitzke (2008) a educação física na educação infantil demonstra que a psicomotricidade evidencia como referencial no trabalho pedagógico. Isso, porque na psicomotricidade não existe as diferenças que caracterizam o indivíduo como a 
deficiência, gênero, etnia, classe social, entre outros, e desta forma constitui-se na escola e na educação infantil como apoio para as aprendizagens cognitivas.

No domínio afetivo e social percebia-se que na mesma classe alguns apresentavam sentimentos diferenciados. Destacando-se três alunos, de modo que uma demonstrava durante as atividades excesso de coragem, a outra demonstrava medo e outro apresentava indisciplina com os colegas. Porém mesmo apresentando características diversificadas auxiliavam-se na realização das tarefas. Negrine (2002) citado por Nitzke (2008) coloca que a atuação das crianças perante jogos e atividades são ferramentas da ação psicomotora que auxilia a formação da personalidade através da participação, criatividade e socialização nessas tarefas.

Avaliamos também, a relação das acadêmicas com a equipe diretiva da escola, a professora de Educação Física, a professora responsável da turma da classe especial e com os alunos. O trabalho foi desenvolvido com o apoio das professoras e da equipe diretiva por demonstrarem interesse no desenvolvimento desse trabalho, o qual foi essencial para que houvesse um ótimo andamento nas atividades e crescimento na formação acadêmica. Houve preparação para que essas aulas acontecessem com êxito, surgindo interesse e dedicação. A relação com os alunos foi construída em cada aula, e no que percebemos a segurança e a confiança por parte deles foi de extrema importância para o andamento das atividades.

\section{CONSIDERAÇÕES FINAIS}

Neste estudo, procuramos contribuir para o desenvolvimento dos domínios motor, cognitivo e afetivo-social dos alunos da classe especial, a partir de um planejamento que teve como base estudos complementares na área da Educação Física seguindo a abordagem psicomotora para a turma de classe especial.

O planejamento a partir da abordagem psicomotora foi com o intuito de estimular os domínios e por acreditar que esta abordagem assume papel relevante para esse tipo de trabalho e para atingir objetivos.

Através da participação dos alunos nas aulas, as quais foram anotadas e discutidas observaram-se melhorias significativas, na realização das atividades e nas relações sociais entre eles e com os colegas da outra classe. Com isso percebemos a importância do componente curricular Educação Física para a classe especial, pois através da prática motora, os alunos vivenciaram atividades que privilegiaram a cooperação, criatividade e a coletividade, sendo essenciais para o desenvolvimento afetivo-social e cognitivo. Assim, os conteúdos desenvolvidos foram importantes para o conhecimento e reconhecimento de seus corpos e de suas potencialidades.

Através dos aspectos positivos encontrados perante essas aulas nessa turma e a interação com a turma de classe regular haverá a continuidade do trabalho, visando à inserção dos alunos da classe especial em turmas regulares no horário da disciplina de Educação Física.

A Educação Física tem função importante na consolidação da educação inclusiva, pois consegue através da prática pedagógica correlacionar a realidade vivenciada pelos alunos, com os conteúdos propostos, dando liberdade de expressão aos que realizam as atividades escolares, e fazendo com que o professor tenha maior 
liberdade para adequar os conteúdos às necessidades dos seus alunos.

\section{REFERÊNCIAS}

ARANTES, A. C. (2005). Educação Física: alguns textos selecionados sobre o estado da arte. Trabalho averbado na Fundação BIBLIOTECA NACIONAL - MEC nro. de Registro: 363.096 Livro: 671 Folha: 256. Qualificado como Didático Pedagógico, 2005. Disponível em http://anacrisarantes. pro.br/trabalhos/os $\% 20$ conteudos $\% 20$ das $\% 20$ aulas $\% 20$ de $\% 20$ educacao $\% 20$ fisica $\% 20$ para $\% 20$ portadores $\% 20$ de\%20necessidades \% 20especiais.pdf Acessado em 01 de março de 2011.

AZEVEDO, E. S; SHIGUNOV, V. Reflexões sobre as Abordagens Pedagógicas em Educação Física. KINEINRevista Eletrônica de Estudo do Movimento Humano. Vol. 1 No. 1, Set - Dez de 2000.

BARRETO, S. J. Psicomotricidade, educação e reeducação. $2^{\circ}$ ed. Blumenau: Livraria Acadêmica, 2000.

BEYER, HUGO OTTO. A Educação Inclusiva: incompletudes escolares e perspectivas de ação. Revista do Centro de Educação, edição: 2003 - № 22. Disponível em http://coralx.ufsm.br/ revce/ceesp/2003/02/a3.htm. Acessado em 08 de maio de 2010.

BRASIL, Ministério da Educação - Secretaria de Educação Especial (SEESP). Política nacional de educação especial na perspectiva da educação inclusiva. Brasília: MEC, 2008.

FALKENBACH, A. P; MEDEIROS, J. A relação professora/aluna com necessidades especiais nas aulas de Educação Física da escola comum. EFDeportes.com, Revista Digital, 2008.

FONSECA, V. Psicomotricidade. $2^{\mathrm{a}}$ ed. São Paulo: Martins Fontes, 1988.

FREITAS, P. e CIDADE, R.E. Noções sobre Educação Física e Esportes para pessoas portadoras de deficiência: uma abordagem para professores de $1^{\circ}$. e $2^{\circ}$. Graus. Uberlândia: Breda, 1997.

GAIO, R. Para além do corpo deficiente: histórias de vida. Jundiaí: Fontoura, 2006.

LIMA, A. S; BARBOSA, S. B (2007). Psicomotricidade na Educação Infantil. Disponível em: http://www. colegiosantamaria.com.br/santamaria/ aprenda-mais/artigos/ver.asp?artigo id $=9$ Acesso em 20 de março de 2011.

MAZZOTTA, M. J. Reflexões sobre inclusão com responsabilidade. Revista @ mbienteeducação, São Paulo, v. 1, n. 2, p. 165-168, ago./dez. 2008.

MONTEIRO, V. A. A psicomotricidade nas aulas de Educação Física escolar: uma ferramenta de auxilio na aprendizagem. Revista Digital - Buenos Aires - Año 12 - No 114 - Noviembre de 2007. Disponível em: http://www.efdeportes. com/efd114/a-psicomotricidade-nasaulas-de-educacao-fisica-escolar.htm

NITZKE, K. Abordagem psicomotora na educação física infantil. Universidade Luterana do Brasil, 2008. Disponível em http://gravatai2.ulbra.tche.br/ interatividades/ultima/nova.html

OLIVEIRA, F. F. Dialogando sobre educação, educação física e inclusão escolar. Revista digital;Año8; $n^{\circ}$ 51. Buenos Aires. Agosto de 2002. Disponível em http://www.efdeportes.com/efd51/ educa.htm. Acessado em 08 de maio de 2010. 
OLIVEIRA, V. M; DUARTE, E. Educação Física, Jogo e Deficiência Mental. In: Sociedade Brasileira de Atividade Motora Adaptada Temas em educação física adaptada / Sociedade Brasileira de Atividade Motora Adaptada. - [S.L.]: SOBAMA, 2001, 101 p.
SÁNCHEZ, P. A. A educação inclusiva: um meio de construir escolas paratodos no século XXI. In: Inclusão: Revista da Educação Especial. Secretaria de Educação Especial/ MEC. Brasília, n.01, p. 07-17, out. 2005.

\title{
AS PHYSICAL EDUCATION CLASSES IN SPECIAL CLASSES IN APPROACH PSYCHO- MOTOR
}

\begin{abstract}
The study is based on an experience of physical education classes in a class Special Class, to demonstrate the importance of this discipline as teaching practice, following the approach psychomotor. The class in question consisted of six children with special educational needs, and took place twice a week, along with a group of regular class. Through the planning and execution of lessons observed the importance of physical education curriculum component as students experienced activities that favored cooperation, creativity and community, reflecting the development motor, cognitive, and affective-social.
\end{abstract}

Keywords: Approach Psychomotor; Special Classes; Phisycal Education.

Recebido em: abril/2013 Aprovado em: junho/2013 